\title{
O papel da Diretoria do Patrimônio Histórico e Artístico Nacional na preservação de sítios e paisagens*
}

* Revista da Diretoria do Patrimônio Histórico e Artístico Nacional, Rio de Janeiro, Brasil, 1968. decreto-lei $n^{\circ} 25$, de 30 de novembro de 1937, que instituiu o Serviço do Patrimônio Histórico e Artístico Nacional), delegou a este órgão do poder público a incumbência de "tombar" os monumentos naturais, incutindo-lhes categoria equivalente à daqueles "bens móveis ou imóveis existentes no país e cuja conservação seja de interesse público quer por sua vinculação a fatos memoráveis da história do Brasil, quer por seu excepcional valor arqueológico ou etnográfico, bibliográfico ou paisagístico".

Realmente, o parágrafo segundo do artigo primeiro do referido diploma diz:

“Equiparam-se aos bens a que se refere o presente artigo e são também sujeitos a tombamento os monumentos naturais, bem como os sítios e paisagens que importe conservar e proteger pela feição notável com que tenham sido dotados pela natureza ou agenciados pela indústria humana".

Em que pese a explicitude desta definição, o maior volume das coisas tombadas pela Diretoria do Patrimônio Histórico e Artísticos Nacional, nestes 30 anos de vigência do Decreto-lei $n^{\circ} 25$, diz respeito àqueles bens construídos pelo homem, sendo realmente ilegível o número de agenciamentos naturais até agora inscritos nos seus Livros de Tombo. Dilapidação

A atual Diretoria do Patrimônio Histórico e Artístico Nacional surgiu num momento em que a vida nacional sofria transformações na sua estrutura socioeconômica favorecendo um processo de dilapidação indiscriminada dos documentos arquitetônicos que balizavam os quatro séculos de formação nacional. Os compromissos de técnica e de economia não foram estranhos à ativação do
Luís Saia

desgaste natural que atingiu todas as construções antigas. Houve até um caso em que um proprietário mandou demolir antiga residência, documento dos mais interessantes do ciclo nordestino do açúcar, a fim de impedir sua preservação pelo poder público.

A organização de um órgão do poder público especialmente incumbido da preservação dos monumentos antigos teria tardado, posto que o maior volume dos antigos edifícios já havia então desaparecido em muitas cidades ou zonas. $\mathrm{Na}$ cidade de São Paulo, documento urbano da maior importância no conjunto da formação nacional, e cuja reconstrução foi iniciada na segunda metade do século passado, na época da instalação das ferrovias, houve no curto período de um século duas outras reconstrução foi iniciada na segunda metade do século passado, na época da instalação das ferrovias, houve no curto período de um século duas outras reconstruções, uma substituindo a taipa pelo tijolo, e outra substituindo o tijolo pelo concreto armado. Tais fatos, somados aos fatos históricos que envolveram a formação dessa cidade, já aniquilada uma vez, no século XVIII, pela fuga de seus habitantes para as zonas de mineração, contribuíram para que esse maior foco de concentração urbana do país e uma das suas cidades mais antigas, se apresente hoje despojada de documentos arquitetônicos de feição urbana capazes de ilustrar os diferentes e sucessivos períodos de sua história.

Na década de 30, não só no caso extremo da cidade de São Paulo mas também em outros pontos do País, a aparência de deterioração dos edifícios e demais instalações tradicionais foi sensivelmente agravada por novas perspectivas de progresso ou, não raro, pela vontade de desfrutar novas perspectivas de progresso. 
Urgia pois salvar os documentos sobreviventes e ameaçados de imediato perecimento. O órgão incumbido desta tarefa, sabiamente orientado pela inteligência esclarecida de Rodrigo M. F. de Andrade soube então selecionar os setores que mereciam o benefício de uma ação o quanto possível intensiva, mesmo que isto ocorresse em detrimento de uma atividade equitativamente distribuída que abrangesse igualmente todos os setores previstos pela lei.

Esta atenção maior na sua intensidade e nos seus resultados, e pode não ter sido a mais fiel no que diz respeito ao texto da lei que teoricamente previa uma atenção igual voltada para os monumentos naturais, mas foi certamente a mais eficiente em face da realidade cujo poder predatório atingia níveis elevados a ponto de justificar uma campanha como a que levou a cabo, a inteligência de Paulo Duarte "Contra o Vandalismo e o Extermínio".

Há que considerar ainda que os termos técnicos que definiam essa intensificação da atividade humana não só se inauguravam no âmbito das cidades e das regiões mais densamente ocupadas, como o seu comparecimento nas áreas do País ainda não economicamente ocupadas, ou apenas raramente exploradas, não se verificava ou, quando nelas atuantes, o faziam com pequena capacidade de atuação. Nestas circunstâncias, a urgência de uma ação protetora se fazia mais premente ou nas cidades ou naqueles pontos do País onde a intervenção humana se verificava com maior intensidade durante os quatro séculos da nossa formação. Tal fato justificava uma ação mais intensiva nas cidades e nas áreas de intensa exploração. Vale dizer, nos documentos arquitetônicos.

A partir de 1950, ou mais precisamente depois da segunda guerra mundial, se inaugura no Brasil a substituição da técnica pela tecnologia e da simples ocupação de tipo capitalista pelo problemático-crítico de consequências racionalistas no que diz respeito ao significado das soluções. Com isto se inaugura também uma escala nova nas características de ocupação do solo e de modificação da paisagem. Estradas concebidas e executadas com obediência a normas atualizadas, instalações como Mataripe e Volta Redonda, represas como a de Três Marias, um tipo de intervenção capaz de competir com os dados da natureza na definição da paisagem. Brasília foi, nesse sentido, um empreendimento capaz de demonstrar a capacidade do homem intervir na natureza rápida e profundamente, desde que armado com dispositivos tecnológicos e livre das limitações capitalistas.

Enquanto a monocultura do café levou século e meio para transfigurar a paisagem de cerca de 300000 quilômetros quadrados e em condições de economia e de cultura que não permitiram à inteligência nacional uma análise bastante de suas consequências e uma previsão aproximada de seus resultados, o potencial intervencionista atual, baseado na tecnologia e no interesse social, se revelou capaz de transformações equivalentes em pouco mais de um decênio. E numa situação mental que permite ao País analisar com bastante aproximação os resultados, qualificando-os tanto na sua contribuição positiva favorável naquilo que diz respeito ao progresso material e à cultura, como naquilo que podem representar de desfalque para o patrimônio do Brasil em termos de perdas irremediáveis. Na verdade, os fatos revelam que os meios disponíveis permitem ao homem atual um tipo de intervenção numa escala pedológica e mesmo geológica, muito mais severa portanto, pelo menos no significado paisagístico imediato, daquela escala edafológica característica das técnicas tradicionais.

Ainda uma razão a mais justificando a necessidade de uma corajosa política de proteção às áreas cuja preservação seja recomendável: os empreendimentos de tipo tecnológico e de profunda repercussão paisagística geralmente trazem à sua ilharga o ônus de uma ocupação tumultuária das faixas lindeiras. No caso brasileiro tal fenômeno é singularmente agravado, seja pela exploração demográfica que caracteriza o estágio atual do nosso crescimento populacional, seja porque essa população contém uma larga margem de deslocamento potencial oriunda da instabilidade econômica que assola vastos contingentes de pessoas de algumas áreas do País.

Em face de tais condições, tudo dava a acreditar que, ao contrário do que aconteceu com o problema de transfiguração da paisagem natural até o momento, a qual teria atingido na parte mais densamente povoada do País cerca de $60 \%$ do total primitivo, nas novas condições a extensividade e a profundidade das consequências serão porque mais rápidas, mais profundas, e porque mais atuantes, de resultados negativos mais irreparáveis. 
Há que considerar também que os altos interesses econômicos e sociais que sustentam os grandes empreendimentos modernos do tipo daqueles desejáveis para o Brasil - frequentemente põem à mostra as contradições entre os sistemas nativos ou tradicionais de ocupação, mesmo naquilo que esses sistemas oferecem como documentos válidos do ponto de vista da cultura. O que aconteceu com os monumentos egípcios situados na área inundável da represa de Assuam - onde se exigiu a participação da UNESCO para salvaguardar monumentos já hoje considerados patrimônio da civilização e não apenas da cultura egípcia - fatos como esse denunciam a necessidade urgente de um alto nível de maturidade problemática que possa prevenir fatos como o que ocorreu com o destombamento do Pico do Itabirito. A validez apenas aparente que amparou os argumentos dos interessados no destombamento desse marco da paisagem do chamado Quadrilátero do Ferro não teria substância se as transações que envolveram a Mina da Cata Branca, do que o referido Pico é apenas uma parte, fossem precedidas do tombamento do Pico, uma parte que representa, segundo os mais autorizados cálculos, cerca de $25 \%$ do disponível e explorável. Essa circunstância de não estar ainda tombado o referido agenciamento paisagísticos na época em que se efetivaram tais transações não invalida um reexame das decisões tomadas, mas adverte a conveniência de uma política de tombamento de agenciamentos naturais segundo os critérios que possam ser firmados pela sua posição teórica e pela experiência.

Nesse sentido se afigura da maior importância - e significativamente oportuna - a ação que se empreende no momento através do projeto de sistematização da área rural e do planejamento urbano de Parati. (Tese apresentada pela Diretoria do Patrimônio Histórico e Artístico Nacional no recente Encontro Sobre Ocupação do Território). $\mathrm{Na}$ verdade, a construção de uma rodovia litorânea ligando Santos ao Rio de Janeiro, isto é, atravessando uma área de fácil acesso para a população das cidades mais populosas do Brasil e que permitirá a ocupação turística de um litoral excepcionalmente aquinhoado pela natureza se esse empreendimento não for acompanhado de iniciativas destinadas a disciplinar essa ocupação e preservar as qualidades paisagísticas que a área oferece com uma generosidade sem par, certamente surgirão problemas de difícil solução, para o
Governo e para a os ocupantes desprevenidos. Não se trata de imobilizar a valorização econômica e humana do empreendimento; trata-se apenas de preservar, nessa faixa no entorno da estrada e a beira mar, justamente aqueles elementos que a qualificam como valor paisagístico e turístico, e de evitar que uma exploração indiscriminada destrua exatamente o que se afigura o motivo maior de sua ocupação.

No tocante à proteção dos monumentos naturais a Diretoria do Patrimônio Histórico e Artístico Nacional se encontra, pois, no momento, face à necessidade de uma ação extensiva do mesmo tipo daquela que enfrentou durante seus primeiros 30 anos de vida com relação aos monumentos arquitetônicos. A menos, é verdade, da experiência que desfruta e das possibilidades de proposições teóricos capazes de fornecer uma visão o quanto possível sistemática do conjunto de problemas que deve abordar e resolver.

E é nesse sentido de uma contribuição à sistemática que assinalamos em seguida um rol de critérios cuja validade individual não implica necessariamente no seu comparecimento exclusivista, posto que devem apenas servir para focalizar melhor os diferentes aspectos do problema, fundando a sua análise em dados objetivos e concretos. No conjunto ideal, esses critérios se congregam em cada caso, aliados para justificar a escolha daquelas áreas "que importe conservar e proteger pela feição notável com que tenham sido dotados pela natureza ou agenciados pela indústria humana".

Embora imaginados com intenção sistemática não aspiram um delineamento completo do quadro problemático a enfrentar. Constituem simplesmente uma hipótese de trabalho.

\section{Critério do valor científico-pedagógico}

A referência a setores devidamente compartimentados do conhecimento (geologia, botânica, zoologia, ecologia, etc.) e a consideração incontornável da ação do homem, inelegível na constituição atual de certas paisagens características do Brasil, multiplica a análise dos testemunhos válidos que devem ser tombados como patrimônio preservável e como exemplo para aulas práticas de campo. 
A excepcionalidade, que é geralmente a primeira virtude a apontar um agenciamento natural para o respectivo tombamento, poderia contradizer, e o faz na aparência, o valor prático de um testemunho destacado para ilustrar um determinado fenômeno ou ocorrência que desfrute da extensão do normal. O Pico de Itabirito, em Minas Gerais, as dunas gigantes de Cabo Frio e Laguna, nos Estados do Rio de Janeiro e Santa Catarina, respectivamente, os recortes caprichosos no costão de basalto que singularizam o Morro dos Mosteiros e Torres, em Santa Catarina, constituem peculiaridades capazes de documentar com maior clareza e mais eficiência pedagógica aquelas ocorrências de onde se originaram. Por alcançarem certa semelhança com construções humanas, o que Ihes confere um alto nível de pitoresco, casos - também de excepcionalidade de Vila Velha, no Paraná, e Sete Cidades, no Piauí, somam ao simples valor documentário e científicopedagógico um valor de natureza estética e de turismo.

Uma sumária inspeção do mapa brasileiro de geológica poderia servir para orientar, numa primeira aproximação, a seleção daquelas áreas onde estariam localizados os testemunhos de cada ocorrência característica. Mas uma primeira pergunta, procedente da consulta indispensável à formação nacional, vem complicar o problema aparentemente simples: no interior ou nas lindes dos diversos compartimentos geológicos? Na verdade, quando se considera a importância que os diferentes quadros geológicos manifestaram na ocupação territorial, não é possível desconhecer a associação em pauta. Os nomes Borda do Campos, Borda da Mata e Mato Dentro denunciam-se na medida em que à cobertura vegetal correspondiam faces geológicos diversas, posto que lindeiros.

A ciência que pretenda organizar o conhecimento cada vez mais completo não pode, especialmente no caso de pesquisa de seus valores expressivos do ponto de vista pedagógico, não pode desconhecer tais compromissos. O que, por sua vez, sugere a virtude de uma política em que se aliem os vários critérios.

Uma sistemática não deve deixar de assinalar os casos de preservação in natura em ocorrências geológicas nas quais os fatores ecológicos, tipos de fossilização e associações mineralógicas e litológicas, etc., se encontrariam preservadas da maneira como se originam, como nas ossadas de mesossauros em Assistência, perto de Rio Claro, no Estado de São Paulo, ou nas ossadas de dinossauros de Peirópolis, em Minas Gerais. Nesta última, o vulto do material e a sua diversidade poderiam até justificar a instalação de uma coisa assim como o Museu do Dinossauro. Até ovos de dinossauros são aí encontrados.

A abordagem de problemas e associações mais complicadas, como os que foram acima apontados, não invalidam aqueles casos mais simples de ocorrências nas quais os fenômenos geológicos são claramente ilustrados, como os casos do Varvito de Itu, em São Paulo, ou as rochas "moutonness" apresentando estrias originadas de escorregamentos glaciais em arenito (Winarfum), no Estado do Paraná e também em Itu, em São Paulo, ou o caso da subida do Bainho, em Santa Catarina, com vegetação preservada em filtitos, ou a coluna estratigráfica entre Nova Horizonte e Alto da Serra Geral, em Criciúma, em Santa Catarina.

Nesta mesma categoria de interesse científicopedagógico se enquadrariam aquelas ocorrências onde as associações botânicas, zoológicas, etc., configuram quadros ecológicos tão perfeitamente definidos e explícitos que assumem, por isso, excepcional valor demonstrativo.

\section{Critério de produção econômica}

A lei brasileira não trava o tombamento com a desapropriação. Toda a ação de preservação será portanto facilitada na medida em que a ocupação econômica da região onde se insere a área tombável estiver ainda em nível incipiente. É o caso das escarpas da Serra do Mar tanto em Parati e Ubatuba (a área tombável deve eventualmente abranger os dois municípios para ganhar compleição condizente com a escala natural) e na subida da Graciosa, isto é, no entorno que fecha a bacia do Paranaguá, e ainda de outras ocorrências semelhantes no que diz respeito aos violentos desníveis que atuam como elementos prevalentes da definição da paisagem. Nada impede que nessas escarpas se permita parcial ocupação, como por exemplo, em trechos cujo desnível não ultrapasse 30\%. Tal permissão se afigura como deixa para definir as limitações que devem disciplinar a exploração econômica das áreas tombadas. No caso dos Aparados (Rio Grande do 
Sul), Campo dos Padres e Morro do Tributo, estes em Santa Catarina, a possibilidade de exploração econômica de tipo agrícola está fora de cogitação, a única saída converge para a exploração turística, para a qual o tombamento pode até representar uma contribuição positiva.

Mas é visível a olho nu o interesse do tombamento anteceder de todo à ocupação econômica. Dos 19 Parques Nacionais citados no Decreto-lei no 51 130, de 3 de agosto de 1961, pelo menos 11 deles, (Rio Negro, Monte Alegre, Grã-Pará, Ivaí, Guaraí, Iguaçu, Emas, Ilha do Bananal, Chapada dos Viadeiros e Serra do (aximbo) tiveram como suporte principal a nula ou incipiente ocupação econômica das zonas onde estão inseridos. Foi uma ação deste tipo que permitiu aos Estados Unidos a instalação de uma notável rede de Parques Nacionais. Em mais da metade da área do Brasil atual essas condições prevalecem e não há motivo algum para que se perca tal oportunidade.

\section{Critério da Vinculação Humana (pré história e história)}

A Lei n 3924, de 26 de julho de 1961, que dispõe sobre monumentos arqueológicos e pré históricos, configura especialmente os casos de sambaquis e tesos, para cujo desmonte e exploração econômica prévia e fiscalização permanente do Poder Público, sem que esta impositura implique no tombamento do local onde ocorre a jazida.

Os agenciamentos onde ocorrem inscrições rupestres, como é o caso dos poções existentes na Serra da Borborema, nas imediações da cidade de Campina Grande, na Paraíba (Fazenda Corta Dedo), e em diferentes rochas expostas do interlande brasileiro, configuram exemplos de documentário pré histórico que pode servir de suporte para o tombamento, o qual deverá ser procedido não apenas em relação ao estrito local das inscrições mas englobando o agenciamento paisagístico em que tais rochas comparecem, posto que é da singularidade deste que certamente decorreu a escolha do local para as inscrições.

O campo da Batalha de Guararapes (processo de tombamento $n^{\circ} 523$ - T), a área da vila de Canudos e o Monte Pascoal exemplificam agenciamentos naturais vinculados a fatos relevantes da história do Brasil e detentores portanto de conteúdos cívico e pedagógico que os recomendam para o tombamento.

Mas a história do presente é porventura tão legítima como aquela do passado. Quando ocorra, pois, uma iniciativa do homem capaz de representar um novo quadro de vivência, parece pertinente que o Poder Público também tome a iniciativa de preservar e conservar aquilo que no novo quadro criado testemunhe seu poder criador e sua capacidade de ação. Um exemplo bem explícito deste gênero de possível tombamento pode ser configurado em determinados agenciamentos originados da construção de grandes reservatórios inicialmente destinados à produção de energia elétrica. É o caso, por exemplo, das represas de Três Marias e Furnas, nas quais a extensão das áreas alagadas é de molde a promover a criação de um novo tipo de paisagem.

\section{Critério do testemunho}

A intervenção do homem na natureza, afeiçoando-a aos seus interesses e intenções transfigura a face primitiva e origina novas contexturas paisagísticas, porventura tão válidas quanto as primitivas. Os testemunhos desses dois polos da intervenção humana, os "restos" da paisagem virgem e o notavelmente característico da paisagem criada pela intervenção do homem são espécies que justificam o interesse de documentar essa própria intervenção. Um testemunho da ocorrência natural do pau-brasil, do pinheiro do Paraná, da cobertura florestal dos sedimentários que balizam a formação pedológica de diferentes regiões do Brasil, devem, pelo que representam de disponibilidades encontradas pelo homem para a sua instalação e como exemplos vivos de equilíbrios biológicos primitivos ou novos, conforme o caso. Dentre os exemplos que legitimam a ação do homem como construtor de paisagens pode ser citado o caso dos coqueirais no litoral nordestino, cuja dominância paisagística atual dependeu sobremaneira de espécie vegetal imposta pelo homem.

Este capítulo envolve problemas de ecologia vegetal e animal, já abordados na "Conferência Técnica Internacional para a Proteção da Natureza", realizada em Lake Succes, em 1949, e para cujo trato parece indispensável a audiência de especialistas em botânica, zoologia, etc. 


\section{Critério estético}

Nenhum critério pode dispensar a parceria do critério estético, posto que é deste que emana aquele valor que atrai o homem e que substancia a indústria de turismo, o interesse do estudo, a intenção de resguardar e proteger, de valorizar e apreciar.

Se nenhum dos critérios acima relacionados tem valor absoluto que lhe permita arcar com exclusividade e responsabilidade de um tombamento, basta-Ihe entretanto a parceria da manifestação positiva do critério estético para alcançar o nível de justificação bastante, posto que o valor estético se afigura como a própria condição limite para que um local, sítio ou paisagem revelem aquela "feição notável com que tenham sido dotados pela natureza ou agenciados pela indústria humana". 